\title{
THE IMPACT OF SMOKING ON THE MORPHOFUNCTIONAL STATE OF PERIODONTAL TISSUES OF YOUNG ORGANISM
}

\author{
Romaniuk A. ${ }^{1}$, Nazaryan R. ${ }^{2}$, Zakut Y. S. ${ }^{2}$, Popova $T_{.}^{2}$, Gargin $V^{2}$ \\ ${ }^{1}$ Sumy State University \\ ${ }^{2}$ Kharkiv National Medical University
}

https://doi.org/10.35339/ic.8.1.47-51

\begin{abstract}
Background. The interrelation of disorders in periodontal tissues with metabolic changes caused, in particular, by a violation of microcirculation, observed namely in smoking but the fact that the effect of smoking on the condition of periodontal tissues at a young age has been studied less than other risk factors deserves special attention. The aim of our study was to experimentally assess the effect of smoking on the morphofunctional state of periodontal tissues in young animals. Materials and methods. Simulation of smoking has been performed with ten-week-old WAG rats using the Boyarchuck chamber. Morphometric studies were performed in the gingival zone which was chosen for morphological interpretation of volumes of specific vascular density in microcirculatory bed, specific density of connective tissue in lamina propria and specific area of tissue with ischemia. The obtained digital data were processed by the methods of variation statistics. Results. Simulation of smoking for four weeks in experimental animals leads to pathological changes in the morphofunctional state of the periodontium with reducing vascular density from $19,44 \pm 1,97 \%$ to $11,03 \pm 1,38 \%$, increasing area of connective tissue from $18,33 \pm 2,71 \%$ to $26,49 \pm 1,24 \%$, spreading area of tissue with ischemia from $1,14 \pm 0,70 \%$ to $6,35 \pm 1,67 \%$. Conclusions. Morphofunctional changes in the periodontium with damage to the structure of the epithelial membrane and changes in its permeability, microcirculatory disorders, sclerotic changes are a manifestation of the initial inflammatory and dystrophic processes that can lead to persistent chronic pathology.
\end{abstract}

Keywords: smoking, oral mucosa, ischemia, microcirculatory bed, periodontitis, histology, experiment.

\section{Introduction}

The interest in determining the epidemiological situation with periodontal disease worldwide is high and raises many unanswered questions, despite significant advances in science and practice in this area for young persons and children especially [1]. In particular, this is due to numerous risk factors that directly or indirectly participate in the occurrence of gingivitis [2]. A close look at this problem is based on the fact that the inflammatory process in periodontal tissues is a potential precursor to periodontitis, which can have nega-

Corresponding Author:

Rozana Nazaryan, MD, PhD, Professor,

Head of the Department of Department

of Pediatric Dentistry and Implantology,

Kharkiv National Medical University,

Kharkiv, Ukraine.

E-mail: rosnazaryan@gmail.com tive health consequences, including systemic conditions that affect quality of life [3, 4]. Epidemiological data on the occurrence of gingivitis in adults worldwide have been significantly studied and analyzed [5]. Most studies examining the prevalence and distribution of gingivitis in young children and adolescents carry the context of some controversy. In childhood, a number of diseases can be prevented or treated, including gingivitis, before they become irreversible, such as preventing the evolution of gingivitis to periodontitis and possibly worsening pre-existing systemic conditions $[2,6]$. This can affect the quality of life of children from the beginning of the disease. Therefore, it is especially important to know the factors associated with gum disease in childhood, which, in turn, will justify and implement better programs for primary and secondary prevention, as well as identify more effective therapeutic approaches. 
One of the unresolved issues of pediatric dentistry is the impact of smoking on the condition of periodontal tissues [7]. The high prevalence of tobacco addiction, difficulties in its diagnosis and treatment, contradictions of ideas about the links of etiopathogenesis have led to a constant interest of researchers in this problem $[8,9]$. Such local factors are most often considered among the starting points in periodontal pathology as dental debris, traumatic injuries, infectious agents, and general, in particular, a constant stress factor which could be presented in smoking [10]. Despite sufficiently elucidated morphological and histochemical aspects of periodontal pathology, there is no clear idea of the primary mechanisms of structural and functional changes in periodontal tissues, the relationship between local disorders of homeostasis and the general state of metabolism [11]. This circumstance explains the need for new comprehensive studies using methods that will eliminate the error in the results, leading to contradictions in the reports on periodontology.

One of the postulates of modern periodontology is the interrelation of disorders in periodontal tissues with somatic metabolic changes caused, in particular, by a violation of microcirculation, observed namely in smoking [12-14]. At the same time, the fact that the effect of smoking on the condition of periodontal tissues at a young age has been studied less than other risk factors deserves special attention.

\section{Purpose, subjects and methods:}

2.1. The purpose of our study was to experimentally assess the effect of smoking on the morphofunctional state of periodontal tissues in young animals.

\subsection{Subjects \& Methods}

Twenty ten-week-old WAG rats (male 8694g) were obtained from the Vivarium of Kharkiv National Medical University. They were kept at a controlled temperature $(21 \pm 20 \mathrm{C})$ and relative humidity (50-70\%), at 12-12 h light-dark cycle and free access to rodent chow and water ad libitum. All experimental procedures were carried out in accordance with the provisions of the European Convention for the Protection of Vertebrate Animals used for Experimental and other Scientific Purposes. The animals were randomly divided into two groups by 10 animals: group 1 (control group) and group 2 consisted of 10 animals exposed to smoking.

Smoking was generated using the Boyarchuck chamber operated in a one-pass mode with the smoking feed controlled externally by a metering pump. This prevented smoking recirculation that could lead to the physical damage of the respiratory epithelial cells. Functionality of the Boyarchuck chamber is based on smoking and fresh air mixing caused when incoming air forced through a small orifice meets a flow of incoming smoking. At the beginning of the experiment, the rats were allowed a period of 2 weeks to adapt to the Boyarchuck chamber. For time adaption, all rats were exposed to the fresh airflow.

The Boyarchuck chamber was turned on, and the rats of Group 2 were exposed to smoking for $15 \mathrm{~min}$. To exposure dilution air was delivered at $6 \mathrm{l} / \mathrm{min}$ and smoking was added at $61 / \mathrm{min}$. The smoking was delivered at a rate of $11 / \mathrm{min}$ per port, a value close to the puffing flow rate.

The animals were removed from the experiment by decapitation under ether anesthesia, after which the lower jaws were prepared. For further histological and histochemical examination, the gum-bone-tooth blocks of the right jaw and the gums of the left jaw were fixed in neutral $10 \%$ formalin. Sections after decalcification of the gum-bone-tooth blocks and standard paraffin proceeding were stained with hematoxylin-eosin, with picrofuxin according to van Gieson, according to Rego. The slides were studied on "Olympus BX-41" microscope with subsequent processing using "Olympus DP-soft, version 3.2" software. Morphometric studies were performed in the gingival zone which was chosen for morphological interpretation [15]. Volumes of specific vascular density in microcirculatory bed (MCB), specific density of connective tissue in lamina propria and specific area of tissue with ischemia [16] were estimated for each group (\%). Black area of tissue was detected as area of ischemia is slides staining according to Rego. The obtained digital data were processed by the methods of variation statistics. Statistical significance was accepted in $\mathrm{p}<0.05$.

\section{Results \& Discussion}

The study of histological specimens of the experimental group showed moderate hyperkeratosis of the epithelium of the intercostal papillae and gingival sulcus, the epithelial attachment with thickening of the stratum corneum on the background of thinning of the spiny and granular layers, papillary smoothing. Own plate was found to have acanthotic cords with increased number of fibroblasts, single leukocytes and sclerosis of reticular layer.

The vessels of microcirculatory bed have been characterized by uneven blood filling with background of isolate vessels that have fallen lumens and presence of blood-empty arterioles and 
capillaries with signs of constriction. Mucoid and fibrinoid swelling have been observed in vascular wall. Endotheliocytes are flattened more often, with signs of desquamation in focus of ischemia in slides stained according to Rego. Simultaneously initial signs of sclerotic processes have been noted in perivascular space in lamina propria. Vascular density of microcirculatory bed (table) according to morphometric studies in comparison with the intact group $(\mathrm{p}<0.05)$. of varying degrees, as well as sclerotic changes. All these signs underlie the pathogenesis of chronic periodontal disease [22, 23]. Further progression of the pathological process in the gums along with an increase in the damaging effects lead to the destruction of the gingival junction of periodontal pockets, destruction of the circular connection [24] with the development and deepening of resorptive changes in bone tissue. In our study, the uncertainty of cellular infiltrates

Morphometric changes of the oral mucosa

\begin{tabular}{|c|c|c|}
\hline \hline Groups & Intact & Smoking \\
\hline Index & & $11.03 \pm 1.38^{*}$ \\
\hline Specific vascular density MCB (\%) & $19.44 \pm 1.97$ & $26.49 \pm 1.24^{*}$ \\
\hline Specific area of connective tissue (\%) & $18.33 \pm 2.71$ & $6.35 \pm 1.67^{*}$ \\
\hline
\end{tabular}

$* \mathrm{p}<0.05$ significant difference between groups.

Connective tissue of lamina propria was shown to have edema and isolate lymphocytes and plasma cells in the perivascular space. There was an increase in the number of fibroblasts. Reticular fibers were less coiled than in the control group, thickened and compacted, in some places with partial homogenization. Collagen fibers were collected in bundles with microfocal hyalinization.

Lymphocytes, macrophages and neutrophilic leukocytes were found in the periodontal space. Capillaries were full-blooded with focal paravasal hemorrhages and hyaline thrombi. Certain morphological changes in periodontal tissues were considered to be a manifestation of inflammatory and dystrophic processes in microcirculation disorders and metabolic disorders [17].

The issue of the role of smoking in the etiopathogenesis of many non-communicable diseases ranks high, and the possible consequences of smoking in periodontal tissues have been regarded as contradictory and require further careful study especially in young age [8] as it could be risk for future changes $[18,19]$ due to widespread form of Tabaco addiction $[20,21]$ in different countries. In our opinion, smoking can be the basis not only for the intensification of pathological changes in the periodontium, but also be a trigger for the emergence of these processes $[8,20]$.

Keeping experimental animals for weeks with continuous simulation of smoking led to morphofunctional changes in periodontal tissues. Four weeks of experimental smoking simulation caused changes in the structure of the epithelial membrane, resulting in violation of its permeability, disruption of the microvascular bed of the connective tissue base of the gums, lymphomacrophage infiltration is noteworthy, which should not be interpreted as a favorable course. Probably, this fact testifies to the gradual development of the chronic pathological process, as edema and alteration of periodontal structures are most often dominant in the morphological picture of the chronic process with a sluggish course, as noted by some researchers [2]. Moreover, changes in the microcirculatory tract, identified in the course of our study, were quite significant in periodontal pathology and were confirmed in a number of scientific studies [17,22].

Thus, our study revealed changes corresponding to the initial stages of chronic pathological process. Disorganization of connec-tive tissue, disturbance of MCB development, consequences of ischemic injuries are important for development of periodontitis. We have shown that vascular dysfunction may link development of hypoxia with activation of connective tissue that leads to sclerotic changes in oral mucosa $[16,24]$ and surrounding organs [25]. However, taking into account the smoking of young people [20], development of adequate treatment and prevention measures $[26,27]$ requires a longer simulation of this condition in experimental animals.

\section{Conclusions}

1) Simulation of smoking for four weeks in experimental animals leads to pathological changes in the morphofunctional state of the periodontium with reducing vascular density from $19,44 \pm 1,97 \%$ to $11,03 \pm 1,38 \%$, increasing area of connective tissue from $18,33 \pm 2,71 \%$ to $26,49 \pm$ $1,24 \%$, spreading area of tissue with ischemia from $1,14 \pm 0,70 \%$ to $6,35 \pm 1,67 \%$.

2) Morphofunctional changes in the periodontium with damage to the structure of the 
epithelial membrane and changes in its permeability, microcirculatory disorders, sclerotic changes are a manifestation of the initial inflammatory and dystrophic processes that can lead to persistent chronic pathology.

Thus, the studies and conclusions indicate the need for further study of the effects of smoking on the condition of periodontal tissues. In the future, it is necessary to study the above indicators after 6 months of the experiment, which will clarify the possibility of adaptation mechanisms, or deepening of dystrophic-inflammatory processes with prolonged chronic exposure to smoking. In addition, special attention needs to be paid to the state of the microcirculatory tract and endothelial disorders in periodontal tissues under the influence of smoking.

Conflict of Interest Statement: The authors declare that the research was conducted in the absence of any commercial or financial relationships that could be construed as a potential conflict of interest.

\section{Funding Statement}

This study is the part of scientific research work "Optimization of early diagnosis, prevention and treatment of oral tissue diseases with smoking addiction", No. 0120U102057, Kharkiv National Medical University, and is funded by Ministry of Health of Ukraine.

\section{References}

1. Bashirian, S., Seyedzadeh-Sabounchi, S., Shirahmadi, S., Karimi-Shahanjarini, A., Soltanian, A. R., \& Vahdatinia, F. (2021). Predictors of oral health promotion behaviors among elementary school children: Examination of an extended social cognitive theory. International journal of paediatric dentistry, 31(2), 191-203. https://doi.org/10.1111/ipd.12659

2. Hasiuk, P. A., Malko, N. V., Vorobets, A. B., Ivanchyshyn, V. V., Rosolovska, S. O., Korniienko, M. M., $\&$ Bedenyuk, O. A. (2020). The intensity of chronic catarrhal gingivitis in children depending on the age. Wiadomosci lekarskie (Warsaw, Poland : 1960), 73(5), 846-849.

3. Xiao, J., Fiscella, K. A., \& Gill, S. R. (2020). Oral microbiome: possible harbinger for children's health. International journal of oral science, 12(1), 12. https://doi.org/10.1038/s41368-020-0082-x

4. Shcherba, V., Havrylenko, Y., Krynytska, I., Marushchak, M., \& Korda, M. (2020). A comparative study of oral microbiocenosis structure in experimental comorbidity-free periodontitis and in periodontitis combined with thyroid dysfunction. Polski merkuriusz lekarski : organ Polskiego Towarzystwa Lekarskiego, 48(283), 32-38.

5. Beketova, G., Kuznetsova, L., Grynevych, O., Broun, T., Momotiuk, L., Motuzka, O., \& Yashchenko, L. (2021). Analysis of the clinical trial results of the flavonoid effects on some cellular immunity indicators in children and adults. Polski merkuriusz lekarski : organ Polskiego Towarzystwa Lekarskiego, 49(289), 44-53.

6. Nazaryan, R., Tkachenko, M., Kovalenko, N., Babai, O., Karnaukh, O., \& Gargin, V. (2019). Analysis of local immunity indicators of the oral cavity and degree of gingivitis depending on mutation of CFTR gene in children with cystic fibrosis. Georgian Medical News, (296), 27-31.

7. Bokor-Bratic M. (2002). Uticaj pusenja na stanje parodoncijuma [Effects of smoking on the periodontium]. Medicinski pregled, 55(5-6), 229-232. https://doi.org/10.2298/mpns0206229b

8. Nazaryan, R., Kryvenko, L., Zakut, Y., Karnaukh, O., \& Gargin, V. (2020). Application of estimated oral health indices in adolescents with tobacco addiction. Polski merkuriusz lekarski : organ Polskiego Towarzystwa Lekarskiego, 48(287), 327-330.

9. Popova, T. M., Gorbach, T. V., Tsygankova, T. I., \& Shushliapina, N. O. (2018). Influence of cigarette smoking duration on endothelial cell function. [Uticaj duaine pusenja cigareta na funkciju endotelijalnih celija] Medicinski Casopis, 52(3), 98-104. doi:10.5937/mckg52-17769

10. Mackenbach, J. P., Damhuis, R. A., \& Been, J. V. (2017). De gezondheidseffecten van roken [The effects of smoking on health: growth of knowledge reveals even grimmer picture]. Nederlands tijdschrift voor geneeskunde, 160, D869.

11. Kim, Y. G., Lee, S. M., Bae, S., Park, T., Kim, H., Jang, Y., Moon, K., Kim, H., Lee, K., Park, J., Byun, J. S., \& Kim, D. Y. (2021). Effect of Aging on Homeostasis in the Soft Tissue of the Periodontium: A Narrative Review. Journal of personalized medicine, 11(1), 58. https://doi.org/10.3390/jpm11010058

12. Karsiyaka Hendek, M., Erkmen Almaz, M., Olgun, E., \& Kisa, U. (2019). Salivary LL-37 and periodontal health in children exposed to passive smoking. International journal of paediatric dentistry, 29(3), 369-374. https://doi.org/10.1111/ipd.12459 
13. Curtis, M. A., Diaz, P. I., \& Van Dyke, T. E. (2020). The role of the microbiota in periodontal disease. Periodontology 2000, 83(1), 14-25. https://doi.org/10.1111/prd.12296

14. Abusleme, L., Hoare, A., Hong, B. Y., \& Diaz, P. I. (2021). Microbial signatures of health, gingivitis, and periodontitis. Periodontology 2000, 10.1111/prd.12362. Advance online publication. https://doi.org/ 10.1111/prd.12362

15. Gargin, V., Radutny, R., Titova, G., Bibik, D., Kirichenko, A., \& Bazhenov, O. (2020). Application of the computer vision system for evaluation of pathomorphological images. Paper presented at the 2020 IEEE 40th International Conference on Electronics and Nanotechnology, ELNANO 2020 - Proceedings, 469-473. doi:10.1109/ELNANO50318.2020.9088898

16. Fesenko, D., Glazunov, O., Nakonechna, O., Nazaryan, R., \& Gargin, V. (2019). Consequences of microsequences of microcirculatory distrurbances of oral mucosa in modeling of rheumatoid arthritis. Georgian Medical News, (295), 137-140.

17. Denga, O., Pyndus, T., Gargin, V., \& Schneider, S. (2017). Influence of metabolic syndrome on condition of microcirculatory bed of oral cavity. Georgian medical news, (273), 99-104.

18. Kulik, T., \& Koziel, S. (2020). Social position in a peer group of school-aged boys and selected biological parameters. Anthropological Review, 83(4), 439-447. doi:10.2478/anre-2020-0032

19. Chmielewski, P. P. (2020). The dynamic nature of ageing: Novel findings, therapeutic avenues and medical interventions. Anthropological Review, 83(1), 75-92. doi:10.2478/anre-2020-0001

20. Olczak-Kowalczyk, D., Tomczyk, J., Gozdowski, D., \& Kaczmarek, U. (2020). Cigarette smoking as an oral health risk behavior in adolescents: A cross-sectional study among polish youths. Anthropological Review, 83(1), 53-64. doi:10.2478/anre-2020-0007

21. Cullen, K. A., Liu, S. T., Bernat, J. K., Slavit, W. I., Tynan, M. A., King, B. A., \& Neff, L. J. (2019). Flavored Tobacco Product Use Among Middle and High School Students - United States, 20142018. MMWR. Morbidity and mortality weekly report, 68(39), 839-844. https://doi.org/10.15585/ mmwr.mm6839a2

22. Stryjewska, K., Pytko-Polonczyk, J., Sagbraaten, S., Sagbraaten, S., \& Stryjewski, P. J. (2020). The oral health of patients with acute coronary syndrome confirmed by means of coronary angiography. Polski merkuriusz lekarski : organ Polskiego Towarzystwa Lekarskiego, 48(283), 23-26.

23. Pawlowicz, A., Tymczyna-Borowicz, B., \& Ptasiewicz, M. (2020). The state of the oral health in patients with type 2 diabetes. Polski merkuriusz lekarski : organ Polskiego Towarzystwa Lekarskiego, 48(283), 27-31.

24. Staples, R. J., Ivanovski, S., \& Vaquette, C. (2020). Fibre guiding scaffolds for periodontal tissue engineering. Journal of periodontal research, 55(3), 331-341. https://doi.org/10.1111/jre.12729

25. Nechyporenko, A. S., Reshetnik, V. M., Alekseeva, V. V., Yurevych, N. O., Nazaryan, R. S., \& Gargin, V. V. (2020). Implementation and analysis of uncertainty of measurement results for lower walls of maxillary and frontal sinuses. Paper presented at the 2020 IEEE 40th International Conference on Electronics and Nanotechnology, ELNANO 2020 - Proceedings, 460-463. doi:10.1109/ ELNANO50318.2020.9088916

26. Avetikov, D., Loza, K., Starchenko, I., Loza, E., \& Marushchak, M. (2015). Experimentalmorphological substantiation of expediency to use the skin glue "Dermabond" for postoperative wound closure. Georgian medical news, (244-245), 90-93.

27. Kovach, I., Kravchenko, L., Khotimska, Y., Nazaryan, R., \& Gargin, V. (2017). Influence of ozone therapy on oral tissue in modeling of chronic recurrent aphthous stomatitis. Georgian medical news, (264), 115-119.

Received: 12-Oct-2020

Accepted: 17-Feb-2021 